\title{
Progression of Hepatic Adenoma to Carcinoma in Ogg1 Mutant Mice Induced by Phenobarbital
}

\author{
Anna Kakehashi, Naomi Ishii, Takahiro Okuno, Masaki Fujioka, Min Gi, \\ Shoji Fukushima, and Hideki Wanibuchi

\begin{abstract}
Department of Molecular Pathology, Osaka City University Graduate School of Medicine, Abeno-Ku, Asahi-Machi 1-4-3, Osaka 545-8585, Japan
\end{abstract} \\ Correspondence should be addressed to Anna Kakehashi; anna@med.osaka-cu.ac.jp
}

Received 22 March 2017; Revised 19 May 2017; Accepted 14 June 2017; Published 13 July 2017

Academic Editor: Laura Giusti

Copyright (c) 2017 Anna Kakehashi et al. This is an open access article distributed under the Creative Commons Attribution License, which permits unrestricted use, distribution, and reproduction in any medium, provided the original work is properly cited.

\begin{abstract}
The carcinogenic potential of phenobarbital (PB) was assessed in a mouse line carrying a mutant $M m h$ allele of the $M m h / O g g 1$ gene encoding the enzyme oxoguanine DNA glycosylase (Ogg1) responsible for the repair of 8-hydroxy-2'-deoxyguanosine (8-OHdG). Mmh homozygous mutant $\left(\mathrm{Ogg} 1^{-/-}\right)$and wild-type $\left(\mathrm{Ogg} 1^{+/+}\right)$male and female, 10-week-old, mice were treated with $500 \mathrm{ppm}$ PB in diet for 78 weeks. Hepatocellular carcinomas (HCCs) were found in PB-treated Ogg1 ${ }^{-1-}$ mice, while $O g g 1^{+/+}$animals developed only hepatocellular adenomas (HCAs) at the same rate. This was coordinated with PB-induced significant elevation of 8-OHdG formation in DNA and cell proliferation in adjacent liver of Ogg1 ${ }^{-1-}$ mice. Proteome analysis predicted activation of transcriptional factor Nrf2 in the livers and HCAs of PB-administered $O g g 1^{+/+}$mice; however, its activation was insufficient or absent in the livers and HCCs of $\mathrm{Oggl}^{-1-}$ mice, respectively. Significant elevation of phase I and II metabolizing enzymes was demonstrated in both $O g g 1^{-/-}$and $O g g 1^{+/+}$animals. Treatment of $O g g 1^{-1-}$ mice with PB resulted in significant elevation of cell proliferation in the liver. These results indicate that PB induced progression from HCA to HCC in $\mathrm{Ogg} 1^{-1-}$ mice, due to persistent accumulation of DNA oxidative base modifications and suppression of Nrf2-mediated oxidative stress response, resulting in significant elevation of cell proliferation.
\end{abstract}

\section{Introduction}

Elevation of oxidant byproducts of intercellular metabolism induces DNA damage which is the key factor in cancer and aging. Furthermore, the age-dependent changes in the efficacy and the rate of DNA repair in mammals regulate the susceptibility to endogenous or exogenous carcinogens [1]. Reactive oxygen species (ROS) induce a variety of lesions in DNA, including oxidized bases, DNA strand breaks, and abasic sites, but most frequently attack the 8 position of guanine producing an oxidative DNA damage marker, 8 -hydroxy-2'-deoxyguanosine $(8-\mathrm{OHdG})$ [2]. The reason of increased frequency of spontaneous GC $\rightarrow$ TA transversion mutations detected in repair-deficient bacterial and yeast cells was reported to be elevated levels of $8-\mathrm{OHdG}$ which is strongly mutagenic, being able to mispair with A residues $[3,4]$.

In previous studies, increase of repair-resistant oxidatively induced clustered DNA lesions in the human oxoguanine glycosylase 1 (Ogg1) gene and other repair enzymes were observed in patients with liver, ovary, kidney, breast, and colon cancers [5]. Furthermore, loss of heterozygosity ( $\mathrm{LOH}$ ) in Ogg1 was suggested to play an important role in the development of human hepatocellular carcinomas (HCC), being an early event in hepatocarcinogenesis [6]. In addition, polymorphisms of DNA repair genes including $O g g 1$ were associated with the overall survival of HCC patients with chronic HBV infection [7]. Decreased expression of Ogg1 and mitochondrial Ogg1 (mtOGG1) were reported with human HCC tissues 
and SNU (Seoul National University) human hepatoma cell lines, respectively [8].

Three enzymes from Saccharomyces cerevisiae and various bacteria are known to prevent spontaneous mutagenesis induced by the 8-OHdG [9]. One of them, the Fpg (MutM) DNA glycosylase-AP lyase, removes the oxidized base from G:C base pairs in duplex DNA. The second one, MutY DNA glycosylase, specifically excises adenine misincorporated during replication, resulting in G-T transversion mutation. The third enzyme, MutT, is a GTPase preventing incorporation of $\mathrm{G}$ opposite misincorporated $\mathrm{A}$ into nascent DNA by hydrolyzing the excess of dGTP. In addition, both mammalian and yeast cells use a distinct DNA glycosylase, the product of the $O g g 1$ gene, to excise nucleotides from DNA. It was reported that cloned human and mouse cDNAs encode distinct nuclear and mitochondrial forms of the enzyme generated by alternative RNA splicing [10-14].

In previous studies, homologues of MutY (MYH) and MutT (MTH) have been identified in mammalian cells $[15,16]$. Moreover, a mammalian homologue of glycosylase/apurinic, apyrimidinic lyase (AP lyase; MutM homologue, $\mathrm{MMH}$ ) has been also identified and cloned $[17,18]$. Previously, Myh and $O g g 1$ knockout mice were demonstrated to develop spontaneously lymphomas and lung and ovary tumors $[15,19]$. However, it still remains unclear how the deletion of these enzymes may affect the susceptibility of animals to chemical carcinogens.

$\mathrm{Mmh} / \mathrm{Ogg} 1$ mutant mice used in our study are characterized by physically normal appearance, but lack nicking activity in liver extracts for substrate DNA containing 8-OHdG. As compared to the wild-type or heterozygous mice, in the tissues of homozygous mice at 9 and 14 weeks of age, 8OHdG levels exhibit 3- and 7-fold elevation, respectively [20]. Furthermore, mutation frequency was substantially elevated bearing transgenic gpt genes $\mathrm{Mmh} / \mathrm{Ogg} 1$ mice [20]. It has been previously reported that administration of potassium bromate $\left(\mathrm{KBrO}_{3}\right)$ to $\mathrm{Ogg} 1$-deficient mice resulted in a tremendous increase ( $\sim 70$-fold) of kidney DNA, with consequent GC $\rightarrow$ TA transversions and deletions [10]. In addition, 3.5-fold increase in mutation frequency during liver regeneration following the partial hepatectomy was observed in $\mathrm{Ogg} 1$ mutant mice administered $\mathrm{KBrO}_{3}$ [21]. Moreover, dimethylarsinic acid $\left(\mathrm{DMA}^{\mathrm{V}}\right)$ was reported to exert carcinogenicity in the lungs of Ogg1 mutant mice [22].

Phenobarbital (PB), an anticonvulsant and a sedative, used as an antiepilepsy drug in humans, is also a nongenotoxic carcinogen and a well-known promoter of hepatocarcinogenesis in vivo and in vitro [23-26]. The promoting effect of $\mathrm{PB}$ at a high dose on hepatocarcinogenesis in rodents has been extensively studied, but reasons for its carcinogenic action have yet to be unequivocally clarified. Increased reactive oxygen species (ROS) generation due to the activity of detoxifying enzymes and formation of $8-\mathrm{OHdG}$ are suggested to be possible mechanisms by which PB may exert carcinogenicity [27]. Chronic PB application is known to induce hepatocellular adenomas (HCAs) but not hepatocellular carcinomas (HCCs) in C57BL/6J, B6D2F1, yellow Avy/A, and agouti A/a mice $[28,29]$, while in D2B6F1 mice, it was reported to induce hepatoblastomas [30]. Differences in the promoting effects of PB between C57BL/6J and DBA mice appeared to correlate with differences in the metabolism/detoxification of this drug [31].

To address the question, how the deletion of $\operatorname{Ogg} 1$ gene may affect the susceptibility of animals to chemical carcinogens, the present study investigated the carcinogenic potential of nongenotoxic carcinogen PB in the Mmh/Ogg1 homozygous mutant mice of $\mathrm{C} 57 \mathrm{BL} / 6 \mathrm{~J}$ background. At the end of the treatment period, multiorgan histopathological, immunohistochemical, biochemical, and proteome analyses were performed focusing on alterations of cell proliferation, apoptosis, formation of oxidative DNA modifications, and protein expression changes in the mouse liver induced by $\mathrm{PB}$.

\section{Materials and Methods}

2.1. Chemicals. PB sodium salt (CAS number 57-30-7) (purity $\geq 98 \%$ ) was purchased from Wako Pure Chemical Industries, Ltd. (Osaka, Japan). Other reagents were from Wako or Sigma.

2.2. Maintenance of Mice. The experimental procedures or the present investigation was approved by the Ethics Committee of the Institutional Animal Care and Use Committee of Osaka City University Graduate School of Medicine, Osaka, Japan (approval number 15011), and performed accordingly to the guidelines set by the National Institute of Health and Public Health Service Policy on the Humane Use and Care of Laboratory Animals. Mmh/Ogg1 mutant $\left(\mathrm{Oggl}^{-/-}\right)$and wild-type $\left(\mathrm{Oggl}^{+/+}\right)$C57BL/6J mice of both sexes were bred (approval number 597) in an animal facility with lighting supplied with a $12 \mathrm{~h}$ light/dark, at a constant temperature of $22 \pm 1^{\circ} \mathrm{C}$, relative humidity of $44 \pm 5 \%$, and given free access to tap water and food ad libitum. Mice were housed in a SPF zone of our animal house during the experiment, where conditions, such as sterilization and autoclaving procedures, handling sterilized reagents, and disposable plastic ware, are strictly controlled. $O g g 1^{-1-}$ and $\mathrm{Ogg} 1^{+/+}$mice were divided by stratified randomization into 4 body weight-matched groups, comprising male and female animals and housed in plastic cages containing wood chips.

The general behavior, moribund state, or possible signs of toxicity were checked in all mice once a day. Animals body weights and water and food consumptions were measured every week for the first 12 weeks and every 4 weeks after that up to week 78 . The signs for euthanization were no response to stimuli or the comatose condition, dyspnea, hypothermia, prostration, body weight loss, severe change of heart rate, or physical appearance. Animals with detected body weight loss were checked more precisely for other signs of sickness.

2.3. Experimental Design. $O g g 1^{-1-}$ and $O g g 1^{+/+}$male and female mice were administered a MF pellet diet (Oriental Yeast Co., Tokyo, Japan) containing $\mathrm{PB}$ at a dose of 0 (control) or $500 \mathrm{ppm}$ for 4 (10 mice/group) or 78 (20 mice/group) weeks, respectively.

In the 4-week experiment (Exp. 1), mice were euthanized under the isoflurane, and livers immediately excised and used 
for the analysis of DNA 8-OHdG formation levels by HPLCECD, immunohistochemical assessment of cell proliferation (PCNA), and apoptosis (ssDNA). In the 78-week experiment (Exp. 2), animals were euthanized under the isoflurane when becoming moribund during the study or at the end of the experiment at week 78, autopsied, and the macroscopic pathological analysis was immediately performed. Mouse tissues and tumors were fixed in $10 \%$ buffered formalin and prepared for the routine histology (hematoxylin and eosin (H\&E) staining) and immunohistochemistry or frozen in liquid nitrogen for proteome analysis.

2.4. Analysis of 8-OHdG Formation. Mouse liver DNA 8OHdG levels were determined in experiment 1 after 4 weeks of $\mathrm{PB}$ treatment at a dose of $500 \mathrm{ppm}$ by an HPLC-ECD method as described previously [32].

2.5. QSTAR Elite Hybrid LC-MS/MS. For QSTAR LC-MS/ MS, samples from mouse liver HCCs, adenomas (HCAs), and surrounding and normal liver of PB-treated and control $O g g 1^{-/-}$and $O g g 1^{+/+}$mice from experiment 2 were prepared in $50 \mu \mathrm{l}$ of $9 \mathrm{M}$ urea/2\% CHAPS lysis buffer. Acetone precipitation was done to remove urea from the lysates. Then, reduction, alkylation, digestion with trypsin, and subsequent peptide labeling for each sample were performed using the AB Sciex iTRAQ Reagent Multi-Plex Kit as previously described [33, 34]. Proteome analysis was carried out using the QSTAR Elite Hybrid mass spectrometer (AB Sciex, Concord, ON, Canada) coupled to a DiNa-AI nano LC System (KYA Technologies, Tokyo, Japan). All reported data were used at $95 \%$ confidence cut-off limit. In quantitative analysis, protein lysates from frozen tumors (HCCs, adenomas) and normal-appearing areas from the liver of $O g g 1^{-1-}$ and $O g g 1^{+/+}$mice treated with $\mathrm{PB}$ at a dose of $500 \mathrm{ppm}$ and controls were digested and labeled with 4-plex iTRAQ reagents according to standard procedures [34, 35]. The pulled liver and tumor samples were labeled as follows. Set 1: 114, normal-appearing liver tissue from the control $O g g 1^{-/-}$male or female mice; 115, HCCs from PB-treated $O g g 1^{-/-}$male or female mice; 116, normal-appearing liver tissue from the control $\mathrm{Ogg} 1^{+/+}$male or female mice; 117 , HCAs from PB-treated $O g g 1^{+/+}$male or female mice. Set 2: 114, surrounding liver tissue from PB-treated $O g g 1^{-/-}$male or female mice; 115, normal-appearing liver tissue from the control Ogg1 $1^{-/-}$male or female mice; 116, surrounding liver tissue from $\mathrm{PB}$-treated $\mathrm{Ogg} \mathrm{1}^{+/+}$male or female mice; normal-appearing liver tissue from the control $\mathrm{Ogg} 1^{+/+}$ male or female mice. Protein concentrations were measured with BCA Protein Assay Kit (Pierce, IL, USA).

2.6. Ingenuity Pathway Analysis (IPA). We utilized the Ingenuity program (Ingenuity Systems, Mountain View, CA) to perform the functional, upstream regulators, pathway, and network analysis for interacting proteins (Ingenuity Systems, Mountain View, CA). Activation of upstream regulators or pathways was measured by $z$-scores. A $z$-score of above or less than 2 was considered significant.

2.7. Immunohistochemical Examination. In experiment 1, immunohistochemical staining for PCNA, a marker of cell proliferation, and apoptosis (single-stranded DNA (ssDNA)) was performed using an anti-PCNA rabbit polyclonal (PC-10, IgG; Santa Cruz Biotechnology Inc., Santa Cruz, CA; $1: 500)$ and rabbit polyclonal ssDNA (IgG, $100 \mu \mathrm{g} / \mathrm{ml}$, Dako Japan Co., Kyoto, Japan; 1:400) antibodies, respectively, in liver sections as described previously using the ABC method [36]. The PCNA and ssDNA indices were estimated with counts of clearly brown/black positive nuclei per 1000 cells.

In experiment 2, differentially expressed proteins in HCCs and HCAs of mice treated PB were further verified by immunohistochemistry. Paraffin sections containing normal, surrounding liver tissue and tumors were used for comparison and stained using standard immunohistochemical methods. Guinea pig polyclonal antibodies against keratins 8 and 18 (KRT8/18) (1:400; Progen Biotechnik, Germany), rat monoclonal antibody against prohibitin 1 (PHB1) (1:300; Risk Assessment and Research Inc., Osaka, Japan), rabbit polyclonal antibody against cytochrome b5A (1:300; Santa Cruz Biotechnology Inc., California, USA), and rabbit monoclonal antibody against phospho-Nrf2 (Ser40) (1:100; Abcam, Tokyo, Japan) were employed. Antigen visualization was performed with 3,3'-diaminobenzidine tetrahydrochloride (Dako Japan). 8-OHdG and PCNA immunohistochemical evaluation was performed as described previously [36]. Different negative controls and antigen retrieval methods were used for optimization of the technique.

2.8. Western Blot Analysis. Livers and liver tumors of control or PB-treated $O g g 1^{-/-}$and $O g g 1^{+/+}$mice were lysed in T-PER Tissue Extraction Reagent ( $\mathrm{pH} 7.6)$ (Pierce Biotechnology, Rockford, IL, USA), containing the proteinase inhibitor. Cell lysates were fractionated using the 10\% SDS-PAGE and transferred to the Immobilon-P Transfer Membrane (Millipore, Billerica, MA). Membranes were incubated with primary antibodies and proteins visualized using an ECL Prime Western Blotting Detection Reagent according to the manufacturer's instructions (Amersham, Buckinghamshire, UK). Rabbit polyclonal antibodies against Nrf2 (ab31163; $1: 1000)$ and rabbit monoclonal antibodies against p-Nrf2 (S40) (ab76026; $1: 3000)$ were from Abcam (Tokyo, Japan) and mouse monoclonal antibody against $\beta$-actin (C4) (sc-47,778; $1: 10,000)$ was from Santa Cruz Biotechnology (Santa Cruz, CA).

2.9. Statistical Analysis. The significance of differences between mean values was analyzed using the StatLight2000(C) program (Yukms Corp., Japan). Kaplan-Meier analysis was conducted to determine the survival rates for $O g g 1^{-/-}$and $O g g 1^{+/+}$mice. The significance of intergroup differences in incidences of findings from gross pathology was analyzed by using Fisher's exact probability test (two sided). Statistical comparisons between the control and experimental groups and between the concomitant $O g g 1^{-/-}$ and $O g g 1^{+/+}$groups for numerical data were assessed using the $F$ test. If homogeneous, the data were analyzed with Student's $t$-test (two sided), and if not, with the Welch test. 


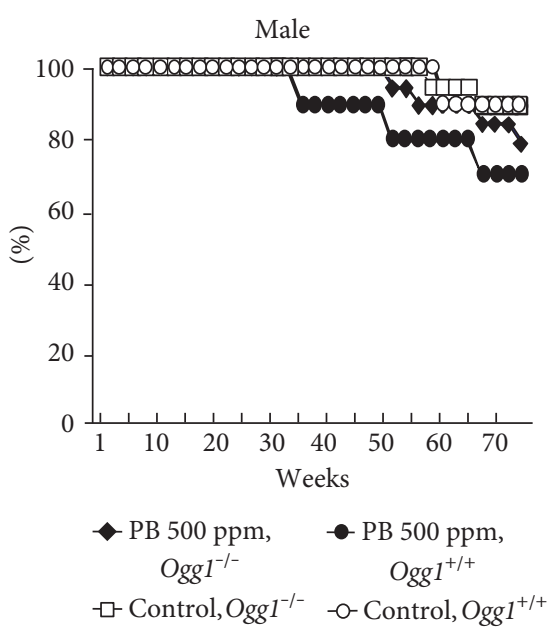

(a)

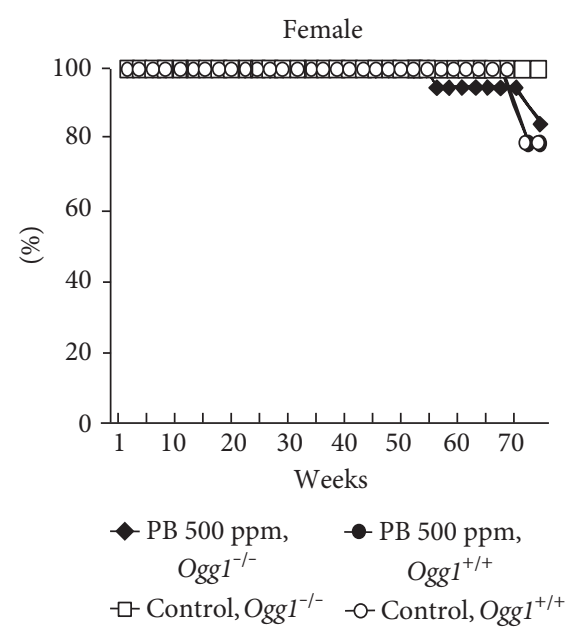

(b)

Figure 1: Survival curves for male (a) and female (b) $O g g 1^{-/-}$and $O g g 1^{+/+}$mice.

\section{Results}

3.1. General Observations. No abnormalities in general condition of animals were found induced by PB treatment and no significant differences among the groups with regard to food and water consumption or body weight gain observed (data not shown). Total PB intake was comparable among Ogg1 homozygous knockout and wild-type mice.

In experiment 2, significant increase in relative liver weights was found in the group of $\mathrm{Oggl}^{-1-}$ (males: $6.3 \pm 1.4 \mathrm{~g}, \quad P<0.0001$; females: $6.2 \pm 1.9 \mathrm{~g}, P<0.01)$ and Ogg1 $1^{+/+}$(males: $8.3 \pm 2.9 \mathrm{~g}, P<0.0001$; females: $6.8 \pm 1.2 \mathrm{~g}$, $P<0.0001)$ mice treated with $\mathrm{PB}$ as compared to corresponding control $O g g 1^{-1-}$ (males: $4.2 \pm 0.6 \mathrm{~g}$; females: $4.9 \pm$ $1.1 \mathrm{~g}$ ) and $O g g 1^{+/+}$(males: $4.9 \pm 1.0 \mathrm{~g}$; females: $4.0 \pm 1.3 \mathrm{~g}$ ) animals. Trends for increase of relative spleen weights in PB-administered $O g g 1^{-1-}$ (males: $0.23 \pm 0.10 \mathrm{~g}$; females: $0.36 \pm 0.17 \mathrm{~g}$ ) and $O g g 1^{+/+}$(males: $0.51 \pm 0.45 \mathrm{~g}$; females: $0.42 \pm 0.23 \mathrm{~g})$ mice as compared to corresponding control Ogg1 $1^{-/-}$(males: $0.16 \pm 0.05$; females: $0.29 \pm 0.14 \mathrm{~g}$ ) and Ogg $1^{+/+}$(males: $0.27 \pm 0.15 \mathrm{~g}$; females: $0.28 \pm 0.10 \mathrm{~g}$ ) mice were detected. Kidney weights did not differ between the PB-treated and control Ogg1 $1^{-/-}$or $O g g 1^{+/+}$groups.

3.2. Survival Curves (Exp. 2). Survival curves for male and female Ogg1 homozygous mutant and wild-type age-matched littermates in experiment 2 are shown in Figures 1(a) and 1(b), respectively. Nontreated female $O g g 1^{-/-}$mice appeared to be healthy and long-lived as compared to the corresponding control $O g g 1^{+/+}$mice. At week 38, the first PB-treated $O g g 1^{+/+}$male mouse with a malignant lymphoma was found. Spontaneous tumors, mostly malignant lymphomas/leukemias, developed in PB-administered $O g g 1^{+/+}$male mice were the reason of their earlier mortality. The number of PB-treated surviving $O g g 1^{-/-}$male and female mice started to decrease at weeks 52 and 55, respectively, mostly due to the development of malignant lymphomas/ leukemias (females) and HCCs (males and females) (Figure 1).
In experiment 2, no $O g g 1^{+/+}$animals died because of the development of liver tumors. In nontreated $O g g 1^{-/-}$male and female mice, the decrease of survival was observed at weeks 60 and 73, respectively (Figure 1).

3.3. Results of Histopathological Examination. Table 1 shows the incidence and general distribution of tumors in PBtreated and control male and female $O g g 1^{-/-}$and $O g g 1^{+/+}$ mice genotypes.

PB-administered $O g g 1^{-1-}$ mice were more susceptible to the induction of tumors as compared to $\mathrm{Ogg1^{-/- }}$ control littermates. PB treatment induced significant increase of total tumor incidence in $O g g 1^{-1-}$ females $(60 \% ; P<0.01)$, as compared to $\mathrm{Ogg1} 1^{-1-}$ control (10\%); however, this effect was not observed in $O g g 1^{+/+}$mice (Table 1).

Neoplastic nodules induced in the PB-treated $O g g 1^{-/-}$ mice were mainly malignant lymphomas/leukemias (females) and liver and lung tumors (Table 1). Histological examination of liver tumors at week 78 in experiment 2 demonstrated that all tumors developing in $O g g 1^{-1-}$ animals administered $\mathrm{PB}$ were well-differentiated HCCs (10\%), while PB-treated Ogg1 $1^{+/+}$animals developed only HCAs at the same rate $(10 \%)$. Thus, in $O g g 1^{-1-}$ mice, progression from HCA to HCC was obvious (Table 1). Malignant lymphomas/leukemias were found in PBtreated $O g g 1^{-/-}$females (35\%), and males (5\%), and differences were significant in females $(P<0.05)$ as compared to control $\mathrm{Ogg1}^{-/-}(0 \%)$ and PB-treated $\mathrm{Ogg1} 1^{+/+}(0 \%)$ mice. In nontreated homozygous mice, lymphomas/leukemias were completely absent, but observed in both sexes in control wild-type animals. Furthermore, lung adenomas were detected in both PB-treated and control $\mathrm{Ogg} 1^{-1-}$ mice. Adenocarcinomas were found in the lungs of PB-administered $\mathrm{Ogg1} 1^{-/-}$males, however, were absent in the PB-treated $O g g 1^{+/+}$group. In addition, uterine tumors (endometrial adenomas and sarcomas) were obvious only in PB-applied $O g g 1^{-1-}$ and $O g g 1^{+/+}$, but not in untreated $O g g 1^{-/-}$and $O g g 1^{+/+}$female mice. 
TABLE 1: Results of the histopathological analysis in $O g g 1^{-1-}$ and $O g g 1^{+/+}$mice.

\begin{tabular}{|c|c|c|c|c|}
\hline \multirow[b]{2}{*}{ Gender } & \multicolumn{2}{|c|}{$\mathrm{PB}, 500 \mathrm{ppm}$} & \multicolumn{2}{|c|}{ Control } \\
\hline & Male & Female & Male & Female \\
\hline \multicolumn{5}{|l|}{$O g g 1^{-1-}$} \\
\hline Number of animals & 20 & 20 & 20 & 20 \\
\hline Number of tumor-bearing mice (\%) & $5(25)$ & $12(60)^{\mathrm{a}}$ & $3(15 \%)^{*}$ & $2(10 \%)^{*}$ \\
\hline Number of tumors/mouse & 0.25 & $0.6^{\mathrm{a}}$ & $0.15^{* *}$ & $0.1^{* *}$ \\
\hline \multicolumn{5}{|l|}{$O g g 1^{+/+}$} \\
\hline Number of animals & 20 & 20 & 20 & 20 \\
\hline Number of tumor-bearing mice (\%) & $10(50)$ & $10(50)$ & $10(50)$ & $10(50)$ \\
\hline Number of tumors/mouse & 0.5 & 0.5 & 0.5 & 0.5 \\
\hline \multicolumn{5}{|l|}{$\operatorname{Ogg} 1^{-1-}$} \\
\hline M. lymphoma/leukemia & $1(5)$ & $7(35)^{\mathrm{a}, * *}$ & 0 & 0 \\
\hline \multicolumn{5}{|l|}{ Liver } \\
\hline $\mathrm{HCA}$ & 0 & 0 & 0 & 0 \\
\hline $\mathrm{HCC}$ & $2(10)$ & $2(10)$ & 0 & 0 \\
\hline \multicolumn{5}{|l|}{ Lung } \\
\hline Adenoma & $1(5)$ & $2(10)$ & $3(15)$ & $2(10)$ \\
\hline Adenocarcinoma & $2(10)$ & 0 & 0 & 0 \\
\hline \multicolumn{5}{|l|}{ Uterus } \\
\hline Endometrial adenoma & - & $1(5)$ & - & 0 \\
\hline \multicolumn{5}{|l|}{ Tumor incidence $(\%)^{\mathrm{b}}$} \\
\hline \multicolumn{5}{|l|}{$\operatorname{Ogg} 1^{+/+}$} \\
\hline M. lymphoma/leukemia & $6(30)$ & 0 & $2(10)$ & $4(20)$ \\
\hline \multicolumn{5}{|l|}{ Liver } \\
\hline $\mathrm{HCA}$ & $2(10)$ & $2(10)$ & 0 & 0 \\
\hline $\mathrm{HCC}$ & 0 & 0 & 0 & 0 \\
\hline \multicolumn{5}{|l|}{ Lung } \\
\hline Adenoma & $2(10)$ & $2(10)$ & 0 & $2(10)$ \\
\hline Adenocarcinoma & 0 & 0 & 0 & 0 \\
\hline \multicolumn{5}{|l|}{ Uterus } \\
\hline Endometrial adenoma & - & $2(10)$ & - & 0 \\
\hline Sarcoma & - & $2(10)$ & - & 0 \\
\hline \multicolumn{5}{|l|}{ Renal } \\
\hline Adenocarcinoma & 0 & 0 & $2(10)$ & 0 \\
\hline \multicolumn{5}{|l|}{ Pituitary gland } \\
\hline Adenoma & 0 & $2(10)$ & 0 & $2(10)$ \\
\hline \multicolumn{5}{|l|}{ Zymbal gland } \\
\hline Adenoma & 0 & 0 & 0 & $2(10)$ \\
\hline \multicolumn{5}{|l|}{ Subcutis } \\
\hline Fibrosarcoma & $2(10)$ & $0 / 0$ & $4(20)$ & 0 \\
\hline \multicolumn{5}{|l|}{ Pancreas } \\
\hline Adenoma & 0 & 0 & $2(10)$ & 0 \\
\hline Ductal adenocarcinoma & 0 & $2(10)$ & 0 & 0 \\
\hline
\end{tabular}

${ }^{\mathrm{a}} P<0.01$ versus the $\mathrm{Ogg} 1^{-/-}$control group; ${ }^{*} P<0.05$ and ${ }^{* *} P<0.01$ versus the control or PB-treated $O g g 1^{+/+}$group. ${ }^{\mathrm{b}}$ Only organs with neoplastic lesions are listed.

3.4. 8-OHdG (HPLC-ECD) (Exp. 1). The levels of 8-OHdG in the liver DNA of control and PB-treated Ogg1 homozygous knockout mice were significantly higher than those observed in their wild-type counterparts $(P<0.0001)$ (Figure 2(a)). PB administration for 4 weeks resulted in comparable significant increases of 8 -OHdG levels in male $(P<0.001)$ and female $(P<0.01) \mathrm{Ogg}^{-1-}$ mice as compared to the respective nontreated controls, but not in $O g g 1^{+/+}$animals, 
8-OHdG

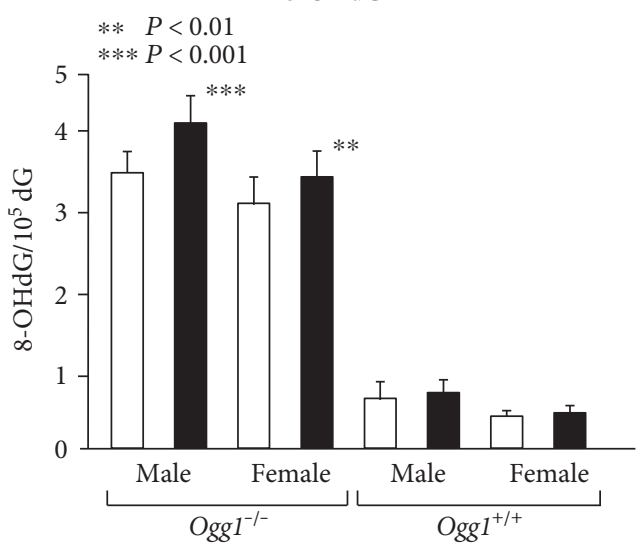

(a)

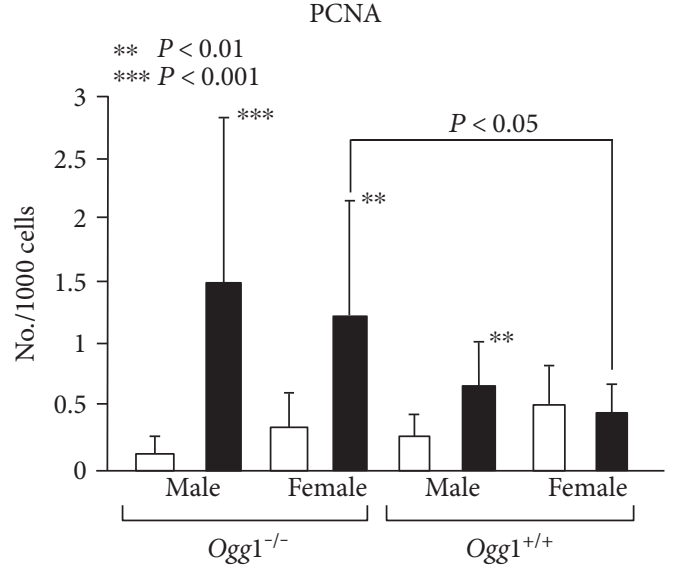

(b)

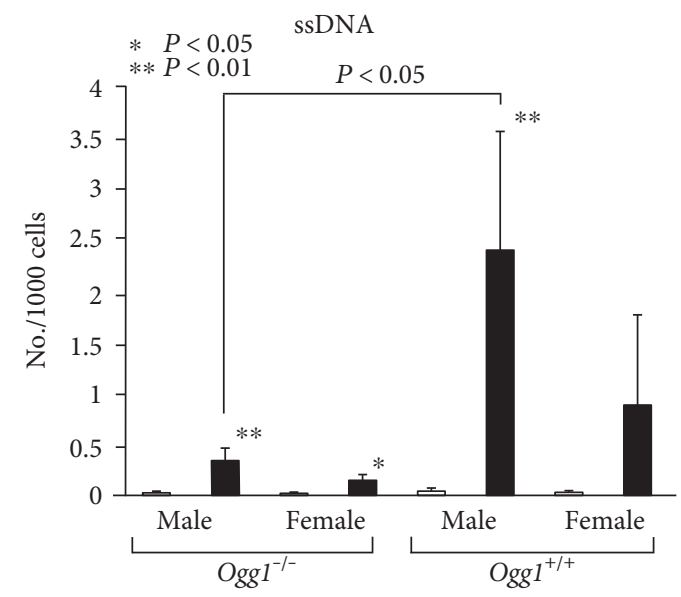

(c)

Figure 2: Formation of 8-OHdG and alterations to cell proliferation and apoptosis (ssDNA) in the livers of $O g g 1^{-/-}$and $O g g 1^{+/+}$mice treated with $\mathrm{PB}$ at 500 ppm for 4 weeks (opened squares: control groups; black squares: PB-treated groups).

indicating that in the wild-type mice, 8 -OHdG is successfully repaired by DNA repair enzymes (Figure 2(a)).

3.5. Alteration to Cellular Proliferation and Apoptosis (Exp. 1). No significant differences of liver PCNA indices were observed between untreated $O g g 1^{-/-}$and $O g g 1^{+/+}$mice. In line with changes of DNA 8-OHdG formation, the significant induction of cell proliferation was found in the livers of male and female $O g g 1^{-1-}$ mice administered PB for 4 weeks, and these values were higher than those observed in PB-treated Ogg1 $1^{+/+}$age-matched littermates (Figure 2(b)). Not high but still significant elevation of cell proliferation induced by $\mathrm{PB}$ was detected in the livers of male but not in female $O g g 1^{+/+}$ mice as compared to $O g g 1^{+/+}$controls.

In experiment 1 , the changes in apoptosis were controversial to that of PCNA (Figure 2(c)). Thus, PB application caused higher elevation of ssDNA positive cell indices in $O g g 1^{+/+}$, as compared to the respective control. In $O g g 1^{-/-}$ mice, small but still significant increase was found, because these values did not vary as much as it was observed with Ogg $1^{+/+}$mice (Figure 2(c)).
3.6. Alteration to Protein Expression Triggered by PB (Exp. 2). The results of the QSTAR Elite MS/MS analysis of differentially expressed proteins in the livers and tumors of $O g g 1^{-1-}$ and $O g g 1^{+/+}$mice, obtained after 78 weeks of $\mathrm{PB}$ administration in diet are presented in Table 2.

In both $O g g 1^{-1-}$ and $O g g 1^{+/+}$PB-treated mice livers, comparable significant overexpression of CAR and PXR downstream enzymes involved in xenobiotic metabolism including CYP2B10, CYP3A11, CYP2A5, CYP1A2, CYP2C54, cytochrome b5 type A (CYB5A), carboxylesterase 1 (CES1), POR, GST alpha 3 (GSTA3) and alpha 4 (GSTA4), GST mu 1 (GSTM1), GST mu 3 (GSTM3), GST mu 5 (GSTM5), UDP-glucose 6-dehydrogenase (UGDH), and paraoxonase 1 (PON1) was demonstrated by proteome analysis. In addition, similar elevation of transferrin (TF), peroxiredoxin 1 (PRDX1) and 3 (PRDX3), and progesterone receptor membrane component 1 (PGRMC1) and downregulation of urea cycle enzymes such as arginase 1 (ARG1), carbamoyl-phosphate synthase 1 (CPS1), argininosuccinate lyase (ASL), ornithine carbamoyltransferase (OTC), and argininosuccinate synthase 1 (ASS1) in the 


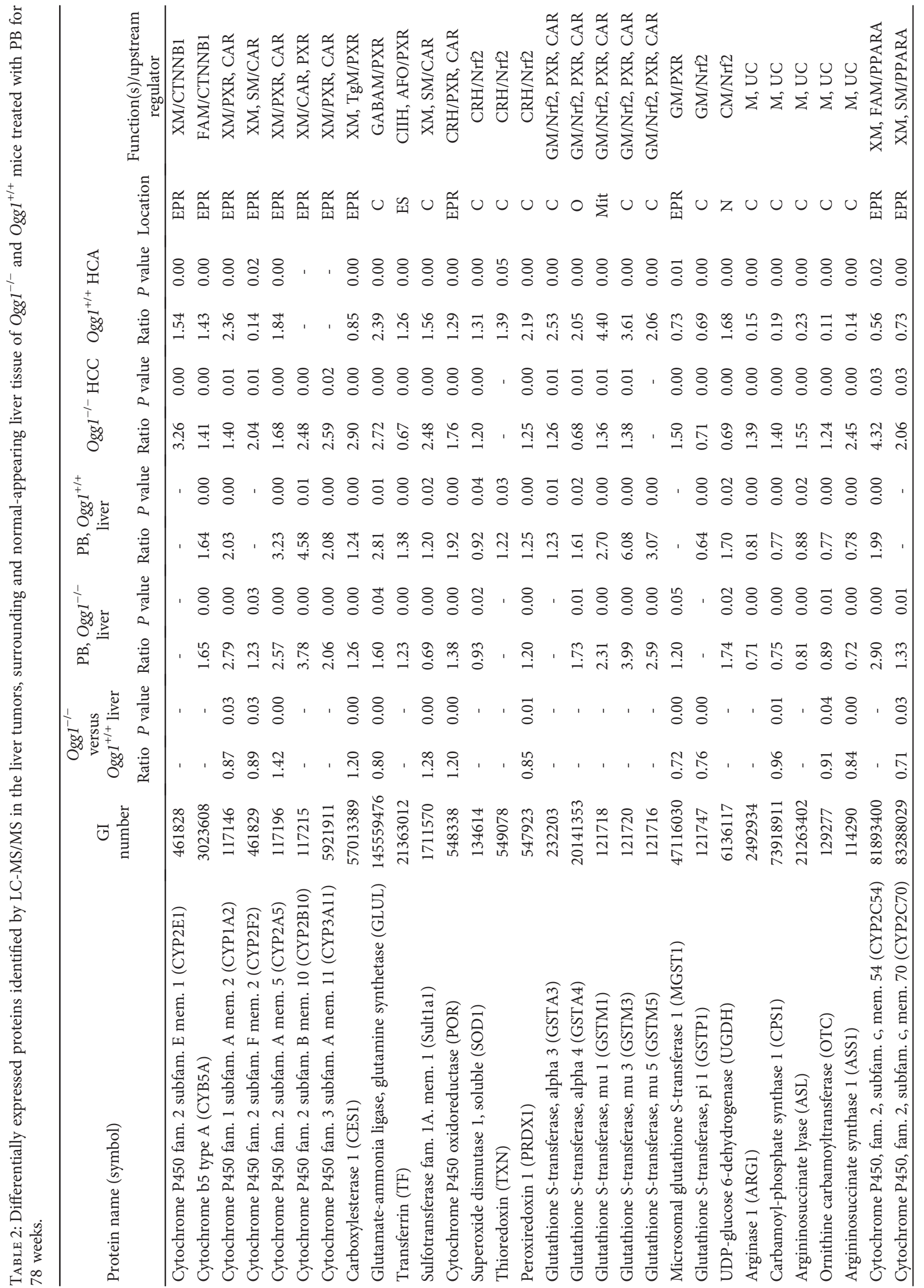




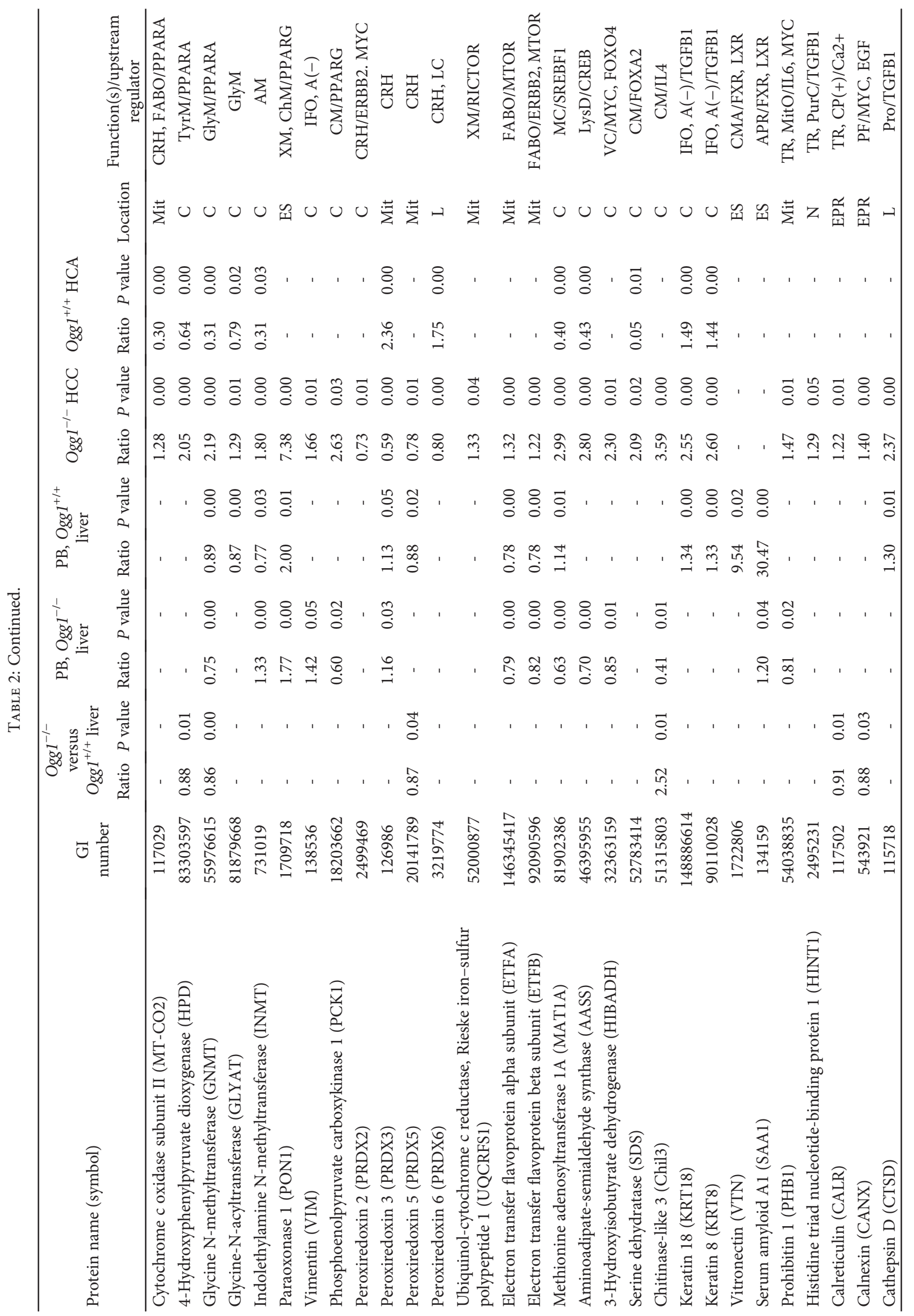




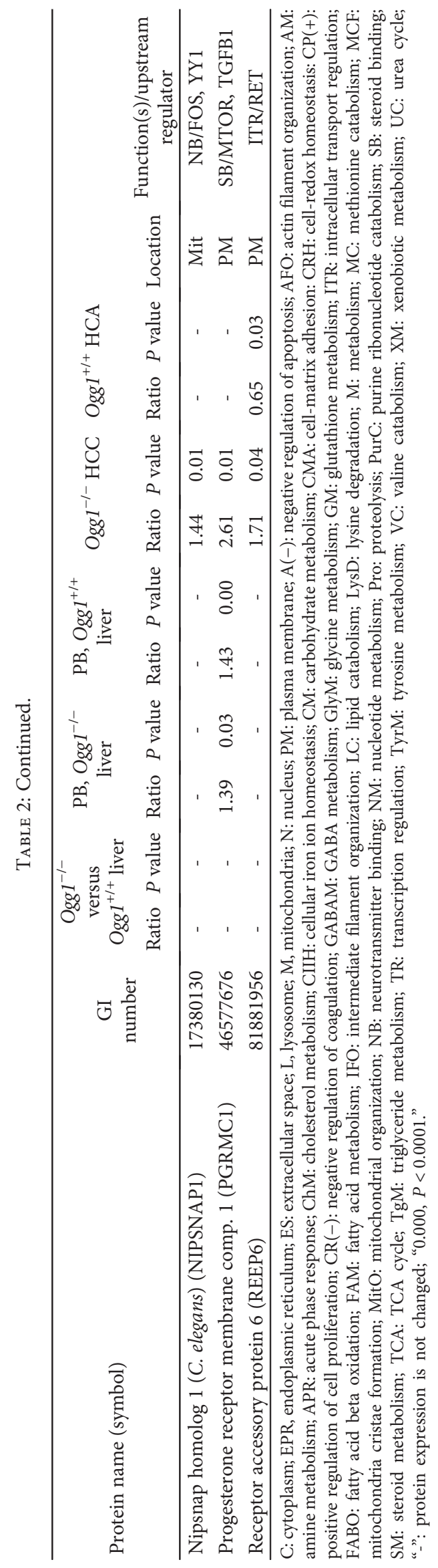


surrounding liver tissue of both the $\operatorname{Ogg} 1^{-/-}$and $\operatorname{Ogg} 1^{+/+}$ $\mathrm{PB}$ groups were found.

Interestingly, downstream proteins of $\mathrm{Nrf} 2$, for instance, GSTs, except GSTP1, were elevated in $\mathrm{Oggl}^{+/+} \mathrm{HCAs}$, but showed only slight increase, no change, or were underexpressed in HCCs of $\mathrm{Oggl}^{-1-}$ mice. Furthermore, elevation of Nrf2-related GSTM1, GSTM3, and GSTM5 in the surrounding liver tissue of $\mathrm{Oggl}^{+/+}$mice administered $\mathrm{PB}$ was higher than in the PB-treated $O g g 1^{-/-}$group. In addition, CYP2E1, the downstream proteins of $\beta$-catenin (CTNNB1) pathway, ubiquinol-cytochrome $c$ reductase, Rieske ironsulfur polypeptide 1 (UQCRFS1), and electron transfer flavoproteins $\alpha$ and $\beta$, involved in MTOR and RICTOR pathways were elevated only in HCCs of the $O g g 1^{-1-}$ PB group. Furthermore, in $O g g 1^{-1-}$ HCCs, significant overexpression of keratins 8 (KRT8) and 18 (KRT18), prohibitin 1 (PHB1), calreticulin (CALR), and histidine triad nucleotide-binding protein 1 (HINT1) transcriptional factors, vimentin (VIM), chitinase-like 3 (Chil3), serine dehydratase (SDS), methionine adenosyltransferase 1A (MAT1A), and PGRMC1 was detected. CYP2B10, CYP3A11, CYP2F2, and CES1, which are CAR and PXR downstream proteins, 4-hydroxyphenylpyruvate dioxygenase (HPD), glycine N-methyltransferase (GNMT), glycine$\mathrm{N}$-acyltransferase (GLYAT), paraoxonase 1 (PON1), and urea cycle enzymes were also overexpressed in PB-treated $O g g 1^{-/-}$HCCs, but not in $O g g 1^{+/+}$HCAs (Table 2). PPAR $\alpha$ downstream CYP2C54 and CYP2C70 were elevated in the livers and HCCs of PB-administered $O g g 1^{-1-}$ mice. Furthermore, level of glutamate-ammonia ligase (glutamine synthetase (GLUL)), an enzyme involved in metabolism of glutamine and gamma aminobutyric acid (GABA), was increased in the livers, HCCs, and HCAs of both PBtreated $O g g 1^{-/-}$and $O g g 1^{+/+}$mice (Table 2). In the normal liver of control $\mathrm{Ogg}^{-1-}$ animals, underexpression of several CAR, PXR, Nrf2, and PPAR $\alpha$ downstream proteins, as well as CALR and CANX was detected, likely being a result of adaptation to high levels of 8-OHdG in the DNA (Table 2).

Canonical pathways, protein functions, and upstream regulator analyses by IPA showed that $\mathrm{PB}$ treatment significantly altered the expression of proteins involved in Nrf2-mediated oxidative stress response in the surrounding liver and HCAs of $O g g 1^{+/+}$mice; however, in the liver and HCCs of the $O g g 1^{-1-}$ group, Nrf2 activation level was low (Table 2 and Table S1 available online at https://doi.org/10. $1155 / 2017 / 8541064)$. On the other hand, expression of CAR- and PXR-related proteins participated in the regulation of LPS/RXR, and xenobiotic metabolism were significantly increased in the livers of both PB-treated $O g g 1^{-/-}$and $O g g 1^{+/+}$animals. Furthermore, synthesis of reactive oxygen species and hydrogen peroxide was activated in $O g g 1^{-1-}$ mouse HCCs, while inflammation and hepatic steatosis were predicted to be increased in the livers of $\mathrm{Ogg1} 1^{-1-}$ mice treated with PB (Table S2). Similarly, results of upstream regulator analysis indicated that CAR and PXR were significantly activated in the surrounding liver tissue of both $O g g 1^{-1-}$ and $O g g 1^{+/+}$PB-treated animals. However, significant activation of Nrf2 transcriptional factor was predicted in surrounding livers and HCAs of $O g g 1^{+/+}$mice, but not in the livers or HCCs of the Ogg1 ${ }^{-1-}$ group (Table S3). In addition, significant activation of $\beta$-catenin was predicted only in $\mathrm{Ogg}^{-1-}$ mice HCCs, while RICTOR activity was increased in both $O g g 1^{+/+}$HCAs and $O g g 1^{-/-}$HCCs.

3.7. Immunohistochemical Evaluation. Significant overexpression of KRT8/18, PHB1, and CYB5A in PB-treated Ogg1 ${ }^{-/-}$mouse HCCs and $O g g 1^{+/+}$HCAs was confirmed by the immunohistochemistry (Figure 3(a) (A-H)). Positive expression of phospho-Nrf2 ( $\mathrm{p}-\mathrm{Nrf2}$ ) was observed in the cell nuclei and cytoplasm of HCAs of the PB-administered $O g g 1^{+/+}$group, while HCCs of $O g g 1^{-/-}$mice were negative (Figure 3(a) (I, J)).

In the surrounding liver tissue of $O g g 1^{-/-}$mice treated with $\mathrm{PB}$ for 78 weeks, increase of $8-\mathrm{OHdG}$ positive expression in the hepatocyte nuclei as compared to the PB-treated $\mathrm{Oggl}^{+/+}$mice and nontreated control $\mathrm{Ogg1^{-/- }}$ mice was obvious (Figure 3(b) (A-D)). Ogg1 $1^{-1-}$ control mice livers were characterized by high 8 -OHdG expression, while $O g g 1^{+/+}$control mouse livers were completely negative. In line with 8-OHdG immunohistochemical results, similar staining pattern with highest expression level in $\mathrm{PB}$ administered $O g g 1^{-1-}$ mice livers was observed for PCNA (Figure 3(b) (E-H)).

3.8. Lack of Nrf2 Activation in $\mathrm{Ogg}^{-1-}$ Mice Livers and HCCs. Western blot analysis demonstrated increase of Nrf2 phosphorylation in the livers and HCAs of PBexposed wild-type mice and, on the contrary, lack of p-Nrf2 expression in the surrounding livers and HCCs of $\mathrm{Ogg1^{-1- }}$ mice (Figure 4(a)). However, overexpression of total Nrf2 protein was detected in both $\mathrm{PB}$-treated $O g g 1^{-1-}$ and $O g g 1^{+/+}$mice tumors and surrounding liver tissues.

\section{Discussion}

The present investigation revealed that long-term administration of nongenotoxic carcinogen $\mathrm{PB}$, which is negative in the Ames test for mutagenicity, caused the progression of hepatocellular adenomas into carcinomas in homozygous Ogg1 mutant mice deficient in 8-OHdG repair without the initiation treatment. In the wild-type C57BL/6J mice used as a background strain for Ogg1 knockout, chronic PB application was previously reported to induce only HCAs but not HCCs [28]. Furthermore, PB has been further suggested to exert a dual role in liver tumor formation by promoting the growth of HCA but inhibiting the growth of HCC [37]. Thus, mutation and inactivation of Ogg1 gene were associated with promotion of mouse hepatocarcinogenesis. Previously, inactivating mutations of DNA repair genes including $O g g 1$ were reported in human liver, ovary, kidney, breast, and colon cancers [5, 38]. Furthermore, it was suggested that a positive correlation exists among human liver cancer stage, 8-OHdG levels, Ogg1 polymorphisms, ALT/GGT levels, telomerase activity, and overexpression of miR-92, a microRNA that plays a role in both the apoptotic process and the cellular proliferation pathways [39]. Our results supported the idea that increase of oxidative base 

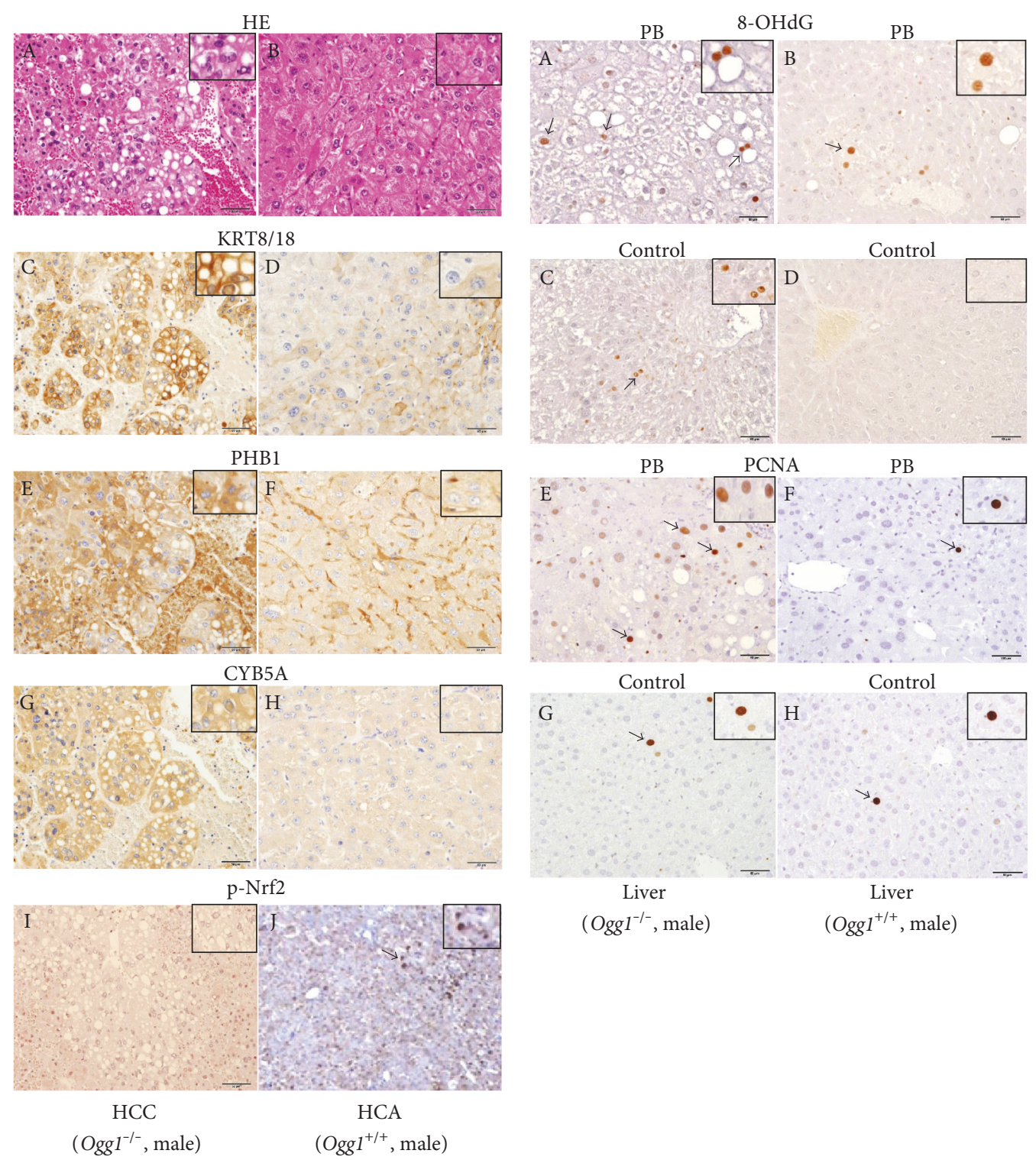

(a)

(b)

Figure 3: (a) Results of H\&E staining and immunohistochemical evaluation of several hepatocarcinogenesis biomarkers (A-H) and p-Nrf2 (I, J) in the livers, HCC (A, C, E, G, and I), and HCA (B, D, F, H, and J) of Ogg1 ${ }^{-1-}$ and $O g g 1^{+/+}$mice maintained on

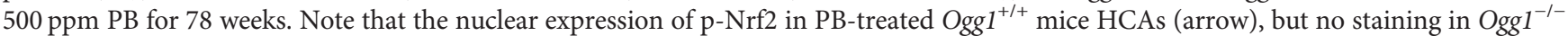
HCCs. (b) Immunohistochemistry for 8-OHdG (A-D) and PCNA (E-H) in the surrounding liver tissue of $O g g 1^{-/-}$and $O g g 1^{+/+}$mice treated with PB for 78 weeks. Note the high expression of 8-OHdG (A) and PCNA (E) in the livers of Ogg1 $1^{-1-}$ mice treated with PB (arrows).

modifications in case of the defective DNA repair is resulted in development of HCC in mice.

Untreated Ogg1 homozygous mutant mice developed spontaneously tumors only in the lungs, which might be due to the significant accumulation of nonrepaired oxidative DNA base modifications in this organ, which is strongly exposed to the molecular oxygen. These data are in line with those reported by Xie et al. [19] and Sakumi et al. [15], demonstrating the spontaneously developed lymphomas, lung and ovary tumors by $O g g 1^{-1-}$ mice. In our study, untreated homozygous mutant, mostly female mice were found to be healthy and long-lived as compared to their wild-type counterparts, in spite of very high level of $8-\mathrm{OHdG}$ in the tissues, indicating that these animals have an adaptation system to high levels of oxidative DNA damage produced due to the knockout of Ogg1 gene. Thus, no lymphomas/leukemias were found in nontreated $\mathrm{Ogg} 1^{-1-}$ mice, therefore, affecting their survival. In the liver of control homozygous mutant mice, one of the possible adaptive mechanisms to high levels of oxidative DNA damage could be related to the downregulation of several CAR-, PXR-, Nrf2-, and PPAR $\alpha$-related proteins, CALR, and CANX. We further observed that $\mathrm{PB}$-treated female homozygous mice were highly susceptible to the development of malignant lymphomas/leukemias, likely being indicative of existing gender differences in response to $\mathrm{PB}$ treatment. 


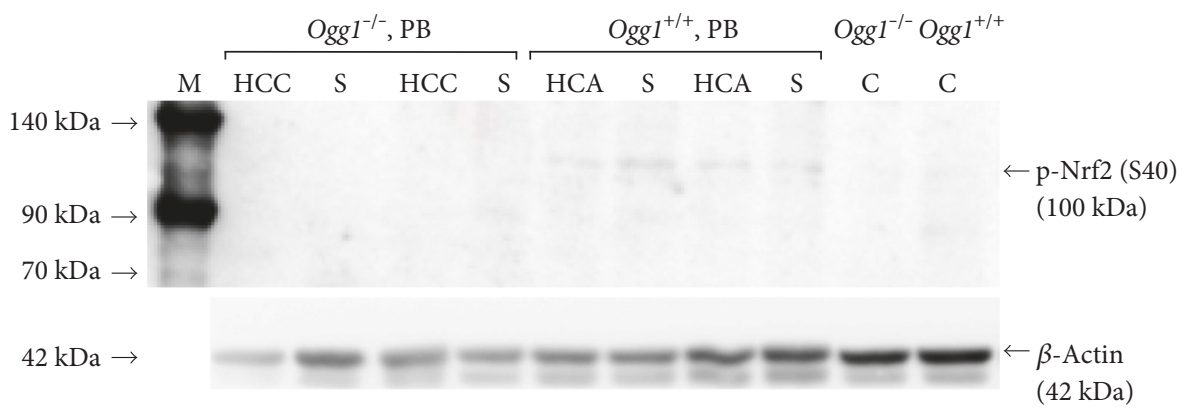

(a)

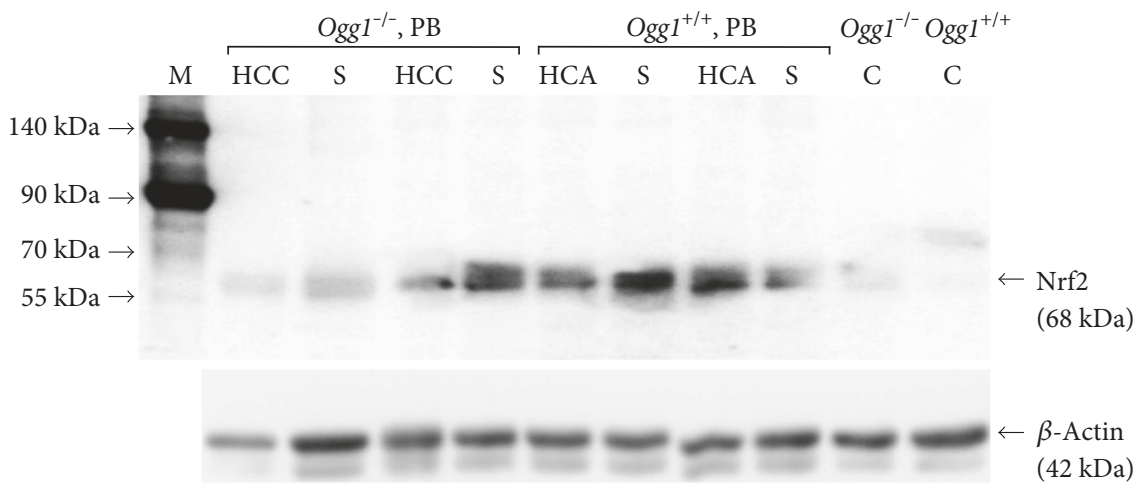

(b)

Figure 4: Representative blots for phospho-Nrf2 (p-Nrf2 (S40)) (a) and total Nrf2 (b) of Ogg1 $1^{-1-}$ and Ogg1 ${ }^{+/+} \mathrm{PB}$-treated and control mice are presented. PB induced elevation of total Nrf2 protein levels in the surrounding liver tissue and liver tumors of Ogg1 null and mostly in the wild-type mice. However, p-Nrf2 was observed only in the livers and HCAs of wild-type animals, indicating that sufficient Nrf2 activation occurs only in PB-administered $O g g 1^{+/+}$mouse livers. HCC: hepatocellular carcinoma; HCA: hepatocellular adenoma; S: surrounding liver tissue; C: untreated control liver.

It has been demonstrated that PB-induced liver-specific DNA damage in mice can be attributed to free radicals, particularly hydroxyl or superoxide radicals arising from the induction of phase I metabolizing enzymes such as cytochrome P450 by PB $[36,40,41]$. The present observation of significant $8-\mathrm{OHdG}$ elevation in the liver DNA induced by $\mathrm{PB}$ in $\mathrm{Ogg} 1^{-/-}$mice is in line with our previous data obtained in rats with regard to promotion of liver carcinogenesis [22]. Furthermore, depletion in cellular glutathione may be correlated with reactive oxygen species mediated oxidative stress [42]. From the results of the proteome analysis, PB application caused significant CAR- and PXR-dependent induction of phase I and II metabolic enzymes in both Ogg1 homozygous mutant and wildtype mice, but insufficient, or no Nrf2 activation in the Ogg $1^{-/-}$livers and HCCs, respectively, pointing out that nonrepaired 8-OHdG and uncontrolled accumulation and damage from the reactive oxygen species in $O g g 1^{-1-}$ liver tissue could become the reason of progression of hepatic adenoma to carcinoma (Figure 5).

In previous studies, mice that lack the Nrf2 transcription factor were more sensitive to the cytotoxic and genotoxic effects of foreign chemicals and oxidants than wild-type animals [43]. In line with our data, Nrf2 ablation has been previously shown to suppress GSTA1, GSTM1, GSTM3, GSTM4, and PRDX1 [43, 44]. Furthermore, Nrf2 has been shown to upregulate the activity of multiple DNA repair pathways, including a pathway involved in the removal of oxidative stress-induced endogenous DNA interstrand crosslinks. In our study, 8-OHdG formation levels were significantly lower in the livers of $O g g 1^{+/+}$mice; therefore, they were more resistant to $\mathrm{PB}$ treatment in comparison with Ogg $1^{-1-}$ due to active DNA repair and Nrf2. It could be suggested that accumulation of unrepaired $8-\mathrm{OHdG}$ in the livers of $\mathrm{PB}$-treated $\mathrm{Ogg} 1^{-1-}$ animals caused a significant increase of cellular proliferation. Our findings point out the existence of interrelation between the base excision repair for oxidative DNA modifications, Nrf2 signaling pathway, and cell proliferation. The defective 8 -OHdG repair was accompanied by lack of Nrf2 phosphorylation, what likely contributed to progression of hepatocarcinogenesis in Ogg1 $1^{-/-}$mice induced by $\mathrm{PB}$. Coordinated overexpression of Ogg1 and Nrf2 and downregulation in Keap1 expression were previously shown in HepG2 human liver cancer cell line after the menadione and $\mathrm{H}_{2} \mathrm{O}_{2} / \mathrm{Fe}^{2+}$ exposure [45]. Furthermore, level of Ogg1 and nuclear translocation of Nrf2 protein were reported to be correlatively decreased upon treatment with PI3K or Akt inhibitors, indicating the existence of crosstalk between Ogg1 and Nrf2 [46]. Furthermore, increase of Nrf2 expression but not its activity was previously shown in human liver cancer samples [47]. However, increase of Nrf2 expression, which could be compensatory, does not 


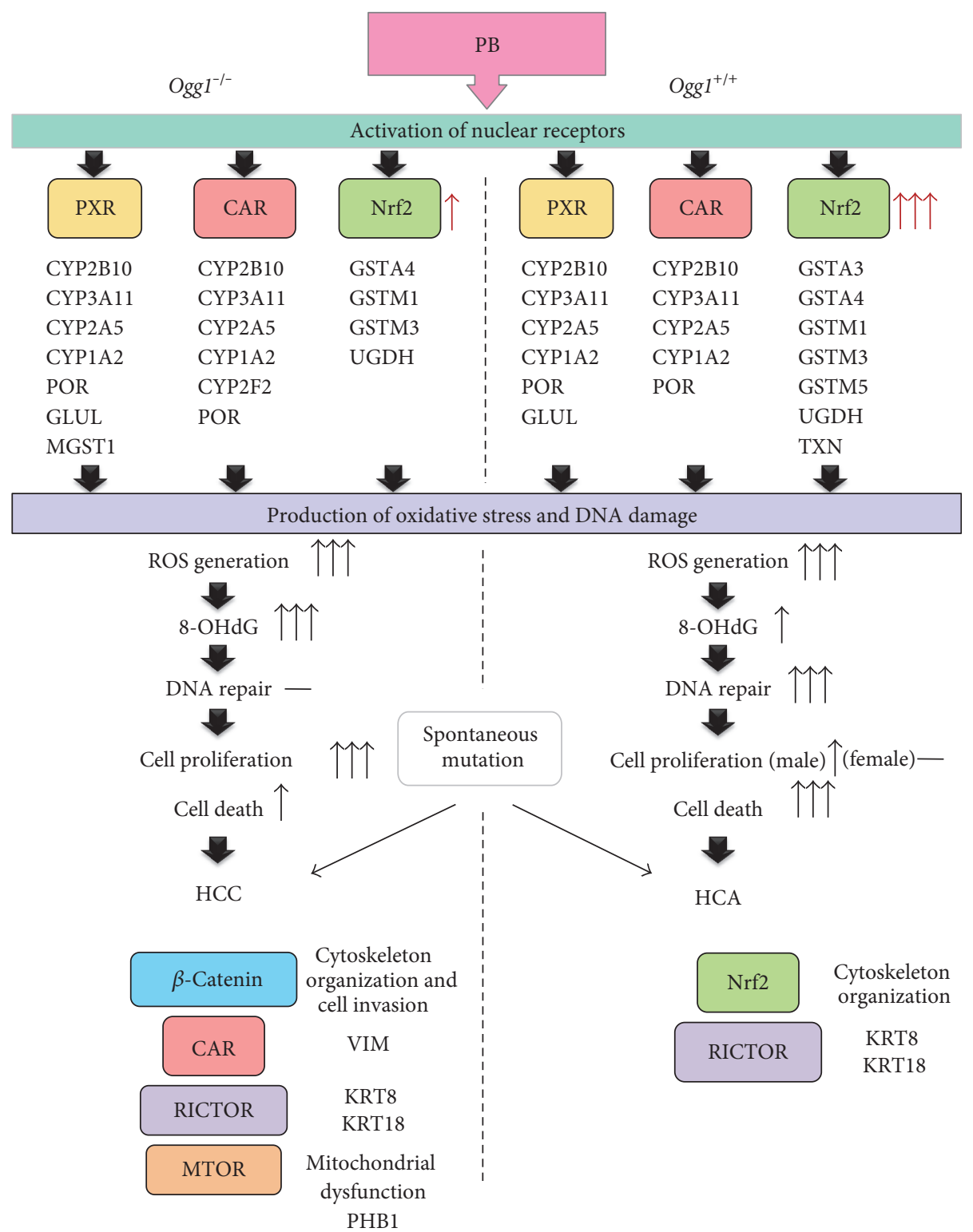

Figure 5: Flow chart on mechanisms of hepatocarcinogenesis in the $O g g 1^{-/-}$and $O g g 1^{+/+}$mice. $\uparrow$ : activation, overexpression, elevation; -: no change.

necessarily mean elevation of its activity, which was reported to be increased due to phosphorylation by oxidative stressactivated different kinases such as ERK, JNK, PKC, and PI3K/AKT, and leads to dissociation of Nrf2 from Keap1 with subsequent nuclear transportation [48]. From our results, in contrast to the wild-type mice, in the livers of Ogg1-deficient animals, Nrf2 phosphorylation and likely its transformation to the nucleus did not occur, resulting in significant increase of oxidative stress and DNA damage of liver cells, and finally, development of HCC.

Previously, an increase in mutation frequency has been shown to be induced by the administration of potassium bromate in $O g g 1^{-1-}$ mouse liver after partial hepatectomy [21]. This study suggested that high levels of cell proliferation are extremely important for the fixation of mutations induced by oxidative stress conditions in the liver. From our results, in $O g g 1^{+/+}$, but not $O g g 1^{-/-}$mice, PB further caused significant elevation of p53-associated apoptosis in the surrounding liver tissue. Previously, we have demonstrated that in about $70 \%$ of cells with DNA-damaged nuclei in the rat liver induced by $\mathrm{PB}$ are apoptotic, suggesting that significant elevation induces DNA fragmentation [36]. Thus, the mechanism of $\mathrm{PB}$ carcinogenicity in the liver of $\mathrm{Ogg} 1^{-/-}$mice could be related to the accumulation of nonrepaired oxidative DNA modifications leading to mutations, elevation of cell proliferation, and suppression of apoptosis what likely resulted in progression of hepatocarcinogenesis.

Significant elevation of proteins inducible by oxidative stress, which could participate in progression of HCA to HCC, such as KRT8, KRT18, PHB1, CALR, and VIM, was 
observed in the $O g g 1^{-/-}$mouse HCCs. In line with the present results, we have previously reported overexpression of KRT8/18 and PHB1 as biomarkers of mouse liver preneoplastic lesions and tumors, showing the highest expression in carcinomas $[34,35,49]$. In addition, here, we observed significant increase of GLUL expression in the livers and tumors of both PB-treated $O g g 1^{-/-}$and $O g g 1^{+/+}$animals. GLUL is present in the brain and liver and is involved in nitrogen homeostasis [50]. Christa et al. reported that GLUL is overexpressed in primary liver cancers, indicating its potential role in the transformation of hepatocytes [50].

In the present study, HCCs developed in PB-treated Ogg1 homozygous mutant mice were further characterized by activation of $\mathrm{Wnt} / \beta$-catenin signaling in association with activation of RICTOR and slight activation of MTOR and CAR signaling. Previously, activation of $\beta$-catenin in human and mouse HCCs have been demonstrated $[51,52]$. In line with our data, single $\beta$-catenin activation has been reported to be insufficient for induction of liver cancer in mice, while combining $\mathrm{CAR}$ and $\beta$-catenin activation resulted in tumorigenesis [53].

\section{Conclusions}

The present results indicate that accumulation of reactive oxygen species and unrepaired oxidative DNA damage produced by $\mathrm{PB}$ is associated with suppression of Nrf2 pathway and significant elevation of cellular proliferation in the livers of $M m h / O g g 1$-deficient mice, likely being related to progression from hepatocellular adenoma to carcinoma.

\section{Conflicts of Interest}

Authors declare that there is no conflict of interest regarding the publication of this article.

\section{Acknowledgments}

The authors thank Masayo Inoue, Kaori Nakakubo, Keiko Sakata, Yuko Hisabayashi, and Rie Onodera for their technical assistance. This work was supported by a Grant-in-Aid for Scientific Research from the Ministry of Health, Labor and Welfare of Japan.

\section{References}

[1] V. N. Anisimov and I. N. Alimova, "The use of mutagenic and transgenic mice for the study of aging mechanisms and age pathology," Advances in Gerontology, vol. 7, pp. 72-94, 2001.

[2] H. Kasai, "Analysis of a form of oxidative DNA damage, 8hydroxy-2'-deoxyguanosine, as a marker of cellular oxidative stress during carcinogenesis," Mutation Research, vol. 387, pp. 147-163, 1997.

[3] D. Nakae, Y. Kobayashi, H. Akai et al., "Involvement of 8-hydroxyguanine formation in the initiation of rat liver carcinogenesis by low dose levels of N-nitrosodiethylamine," Cancer Research, vol. 57, pp. 1281-1287, 1997.

[4] H. M. Shen, C. N. Ong, B. L. Lee, and C. Y. Shi, "Aflatoxin B1induced 8-hydroxydeoxyguanosine formation in rat hepatic DNA," Carcinogenesis, vol. 16, pp. 419-422, 1995.
[5] S. Nowsheen, R. L. Wukovich, K. Aziz et al., "Accumulation of oxidatively induced clustered DNA lesions in human tumor tissues," Mutation Research, vol. 674, pp. 131-136, 2009.

[6] W. M. Cong, S. H. Zhang, Z. H. Xian, W. Q. Wu, and M. C. $\mathrm{Wu}$, "Study on loss of heterozygosity and microsatellite instability in hepatocellular carcinoma," Zhonghua Bing li Xue Za Zhi, vol. 34, pp. 71-74, 2005.

[7] S. W. Jung, N. H. Park, J. W. Shin et al., "Polymorphisms of DNA repair genes in Korean hepatocellular carcinoma patients with chronic hepatitis B: possible implications on survival," Journal of Hepatology, vol. 57, pp. 621-627, 2012.

[8] Y. K. Lee, H. G. Youn, H. J. Wang, and G. Yoon, "Decreased mitochondrial OGG1 expression is linked to mitochondrial defects and delayed hepatoma cell growth," Molecules and Cells, vol. 35, pp. 489-497, 2013.

[9] A. Klungland, I. Rosewell, S. Hollenbach et al., "Accumulation of premutagenic DNA lesions in mice defective in removal of oxidative base damage," Proceedings of the National Academy of Sciences of the United States of America, vol. 96, pp. 13300-13305, 1999.

[10] T. Arai, V. P. Kelly, O. Minowa, T. Noda, and S. Nishimura, "High accumulation of oxidative DNA damage, 8-hydroxyguanine, in $M m h / O g g 1$ deficient mice by chronic oxidative stress," Carcinogenesis, vol. 23, pp. 2005-2010, 2002.

[11] M. Bjoras, L. Luna, B. Johnsen et al., "Opposite basedependent reactions of a human base excision repair enzyme on DNA containing 7,8-dihydro-8-oxoguanine and abasic sites," The EMBO Journal, vol. 16, pp. 6314-6322, 1997.

[12] R. Lu, H. M. Nash, and G. L. Verdine, "A mammalian DNA repair enzyme that excises oxidatively damaged guanines maps to a locus frequently lost in lung cancer," Current Biology, vol. 7, pp. 397-407, 1997.

[13] J. P. Radicella, C. Dherin, C. Desmaze, M. S. Fox, and S. Boiteux, "Cloning and characterization of hOGG1, a human homolog of the OGG1 gene of Saccharomyces cerevisiae," Proceedings of the National Academy of Sciences of the United States of America, vol. 94, pp. 8010-8015, 1997.

[14] T. A. Rosenquist, D. O. Zharkov, and A. P. Grollman, "Cloning and characterization of a mammalian 8-oxoguanine DNA glycosylase," Proceedings of the National Academy of Sciences of the United States of America, vol. 94, pp. 7429-7434, 1997.

[15] K. Sakumi, Y. Tominaga, M. Furuichi et al., "Ogg1 knockoutassociated lung tumorigenesis and its suppression by Mth1 gene disruption," Cancer Research, vol. 63, pp. 902-905, 2003.

[16] M. M. Slupska, C. Baikalov, W. M. Luther, J. H. Chiang, Y. F. Wei, and J. H. Miller, "Cloning and sequencing a human homolog (hMYH) of the Escherichia coli mutY gene whose function is required for the repair of oxidative DNA damage," Journal of Bacteriology, vol. 178, pp. 3885-3892, 1996.

[17] H. Aburatani, Y. Hippo, T. Ishida et al., "Cloning and characterization of mammalian 8-hydroxyguanine-specific DNA glycosylase/apurinic, apyrimidinic lyase, a functional mutM homologue," Cancer Research, vol. 57, pp. 21512156, 1997.

[18] T. Roldan-Arjona, Y. F. Wei, K. C. Carter et al., "Molecular cloning and functional expression of a human cDNA encoding the antimutator enzyme 8-hydroxyguanine-DNA glycosylase," Proceedings of the National Academy of Sciences of the United States of America, vol. 94, pp. 8016-8020, 1997.

[19] Y. Xie, H. Yang, C. Cunanan et al., "Deficiencies in mouse $M y h$ and $O g g 1$ result in tumor predisposition and G to T mutations 
in codon 12 of the K-ras oncogene in lung tumors," Cancer Research, vol. 64, pp. 3096-3102, 2004.

[20] O. Minowa, T. Arai, M. Hirano et al., "Mmh/Ogg1 gene inactivation results in accumulation of 8-hydroxyguanine in mice," Proceedings of the National Academy of Sciences of the United States of America, vol. 97, pp. 4156-4161, 2000.

[21] T. Arai, V. P. Kelly, K. Komoro, O. Minowa, T. Noda, and S. Nishimura, "Cell proliferation in liver of $\mathrm{Mmh} / \mathrm{Ogg} 1$-deficient mice enhances mutation frequency because of the presence of 8-hydroxyguanine in DNA," Cancer Research, vol. 63, pp. 4287-4292, 2003.

[22] A. Kinoshita, H. Wanibuchi, K. Morimura et al., "Carcinogenicity of dimethylarsinic acid in Ogg1-deficient mice," Cancer Science, vol. 98, pp. 803-814, 2007.

[23] W. H. Butler and V. Hempsall, "Histochemical observations on nodules induced in the mouse liver by phenobarbitone," The Journal of Pathology, vol. 125, pp. 155-161, 1978.

[24] D. Feldman, R. L. Swarm, and J. Becker, "Ultrastructural study of rat liver and liver neoplasms after long-term treatment with phenobarbital," Cancer Research, vol. 41, pp. 2151-2162, 1981.

[25] S. Manjeshwar, E. Laconi, A. Sheikh, P. M. Rao, S. Rajalakshmi, and D. S. Sarma, "In vitro and in vivo response of hepatocytes from hepatic nodules to the mitoinhibitory effects of phenobarbital," Carcinogenesis, vol. 15, pp. 19631968, 1994.

[26] C. Peraino, E. F. Staffeldt, D. A. Haugen, L. S. Lombard, F. J. Stevens, and R. J. Fry, "Effects of varying the dietary concentration of phenobarbital on its enhancement of 2acetylaminofluorene-induced hepatic tumorigenesis," Cancer Research, vol. 40, pp. 3268-3273, 1980.

[27] J. E. Klaunig, Y. Xu, J. S. Isenberg et al., "The role of oxidative stress in chemical carcinogenesis," Environmental Health Perspectives, vol. 106, Supplement 1, pp. 289-295, 1998.

[28] M. A. Pereira, J. E. Klaunig, S. L. Herren-Freund, and R. J. Ruch, "Effect of phenobarbital on the development of liver tumors in juvenile and adult mice," Journal of the National Cancer Institute, vol. 77, pp. 449-452, 1986.

[29] G. L. Wolff, J. E. Leakey, J. J. Bazare, J. R. Harmon, P. J. Webb, and M. G. Law, "Susceptibility to phenobarbital promotion of hepatotumorigenesis: correlation with differential expression and induction of hepatic drug metabolizing enzymes in heavy and light male (C3H x VY) F1 hybrid mice," Carcinogenesis, vol. 12, pp. 911-915, 1991.

[30] B. A. Diwan, J. R. Henneman, and J. M. Rice, "Further evidence for promoter-dependent development of hepatoblastoma in the mouse," Cancer Letters, vol. 89, pp. 29-35, 1995.

[31] B. A. Diwan, J. M. Rice, and J. M. Ward, "Strain-dependent effects of phenobarbital on liver tumor promotion in inbred mice," Progress in Clinical and Biological Research, vol. 331, pp. 69-83, 1990.

[32] H. Kasai, "A new automated method to analyze urinary 8-hydroxydeoxyguanosine by a high-performance liquid chromatography-electrochemical detector system," Journal of Radiation Research, vol. 44, pp. 185-189, 2003.

[33] M. Gluckmann, K. Fella, D. Waidelich et al., "Prevalidation of potential protein biomarkers in toxicology using iTRAQ reagent technology," Proteomics, vol. 7, pp. 1564-1574, 2007.

[34] A. Kakehashi, N. Ishii, T. Shibata et al., "Mitochondrial prohibitins and septin 9 are implicated in the onset of rat hepatocarcinogenesis," Toxicological Sciences, vol. 119, pp. 61-72, 2011.
[35] A. Kakehashi, M. Inoue, M. Wei, S. Fukushima, and H. Wanibuchi, "Cytokeratin 8/18 overexpression and complex formation as an indicator of GST-P positive foci transformation into hepatocellular carcinomas," Toxicology and Applied Pharmacology, vol. 238, pp. 71-79, 2009.

[36] A. Kinoshita, H. Wanibuchi, S. Imaoka et al., "Formation of 8-hydroxydeoxyguanosine and cell-cycle arrest in the rat liver via generation of oxidative stress by phenobarbital: association with expression profiles of p21 $1^{\mathrm{WAF} 1 / \mathrm{Cip} 1}$, cyclin D1 and Ogg1," Carcinogenesis, vol. 23, pp. 341-349, 2002.

[37] A. Braeuning, A. Gavrilov, M. Geissler et al., "Tumor promotion and inhibition by phenobarbital in livers of conditional Apc-deficient mice," Archives of Toxicology, vol. 90, pp. 1481-1494, 2016.

[38] B. Singh, A. Chatterjee, A. M. Ronghe, N. K. Bhat, and H. K. Bhat, "Antioxidant-mediated up-regulation of OGG1 via NRF2 induction is associated with inhibition of oxidative DNA damage in estrogen-induced breast cancer," BMC Cancer, vol. 13, p. 253, 2013.

[39] R. Cardin, M. Piciocchi, A. Sinigaglia et al., "Oxidative DNA damage correlates with cell immortalization and mir92 expression in hepatocellular carcinoma," BMC Cancer, vol. 12, p. 177, 2012.

[40] A. Kinoshita, H. Wanibuchi, K. Morimura et al., "Phenobarbital at low dose exerts hormesis in rat hepatocarcinogenesis by reducing oxidative DNA damage, altering cell proliferation, apoptosis and gene expression," Carcinogenesis, vol. 24, pp. 1389-1399, 2003.

[41] D. J. Waxman and L. Azaroff, "Phenobarbital induction of cytochrome P-450 gene expression," The Biochemical Journal, vol. 281, Part 3, pp. 577-592, 1992.

[42] G. Y. Liou and P. Storz, "Reactive oxygen species in cancer," Free Radical Research, vol. 44, pp. 479-496, 2010.

[43] S. A. Chanas, Q. Jiang, M. McMahon et al., "Loss of the Nrf2 transcription factor causes a marked reduction in constitutive and inducible expression of the glutathione S-transferase Gsta1, Gsta2, Gstm1, Gstm2, Gstm3 and Gstm4 genes in the livers of male and female mice," The Biochemical Journal, vol. 365, pp. 405-416, 2002.

[44] N. Wakabayashi, K. Itoh, J. Wakabayashi et al., "Keap1-null mutation leads to postnatal lethality due to constitutive Nrf2 activation," Nature Genetics, vol. 35, pp. 238-245, 2003.

[45] L. Deferme, J. J. Briede, S. M. Claessen, R. Cavill, and J. C. Kleinjans, "Cell line-specific oxidative stress in cellular toxicity: a toxicogenomics-based comparison between liver and colon cell models," Toxicology in Vitro, vol. 29, pp. 845-855, 2015.

[46] K. C. Kim, I. K. Lee, K. A. Kang et al., "7,8-Dihydroxyflavone suppresses oxidative stress-induced base modification in DNA via induction of the repair enzyme 8-oxoguanine DNA glycosylase-1," BioMed Research International, vol. 2013, Article ID 863720, 10 pages, 2013.

[47] M. Zhang, C. Zhang, L. Zhang et al., "Nrf2 is a potential prognostic marker and promotes proliferation and invasion in human hepatocellular carcinoma," BMC Cancer, vol. 15, p. 531, 2015.

[48] C. Xu, X. Yuan, Z. Pan et al., "Mechanism of action of isothiocyanates: the induction of ARE-regulated genes is associated with activation of ERK and JNK and the phosphorylation and nuclear translocation of Nrf2," Molecular Cancer Therapeutics, vol. 5, pp. 1918-1926, 2006. 
[49] A. Kakehashi, A. Kato, M. Inoue et al., "Cytokeratin 8/18 as a new marker of mouse liver preneoplastic lesions," Toxicology and Applied Pharmacology, vol. 242, pp. 47-55, 2010.

[50] L. Christa, M. T. Simon, J. P. Flinois, R. Gebhardt, C. Brechot, and C. Lasserre, "Overexpression of glutamine synthetase in human primary liver cancer," Gastroenterology, vol. 106, pp. 1312-1320, 1994.

[51] C. M. Wong, S. T. Fan, and I. O. Ng, "Beta-catenin mutation and overexpression in hepatocellular carcinoma: clinicopathologic and prognostic significance," Cancer, vol. 92, pp. 136145, 2001.

[52] A. Kakehashi, V. E. Stefanov, N. Ishii et al., "Proteome characteristics of non-alcoholic steatohepatitis liver tissue and associated hepatocellular carcinomas," International Journal of Molecular Sciences, vol. 18, 2017.

[53] B. Dong, J. S. Lee, Y. Y. Park et al., "Activating CAR and betacatenin induces uncontrolled liver growth and tumorigenesis," Nature Communications, vol. 6, p. 5944, 2015. 


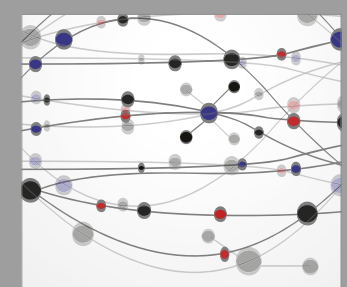

The Scientific World Journal
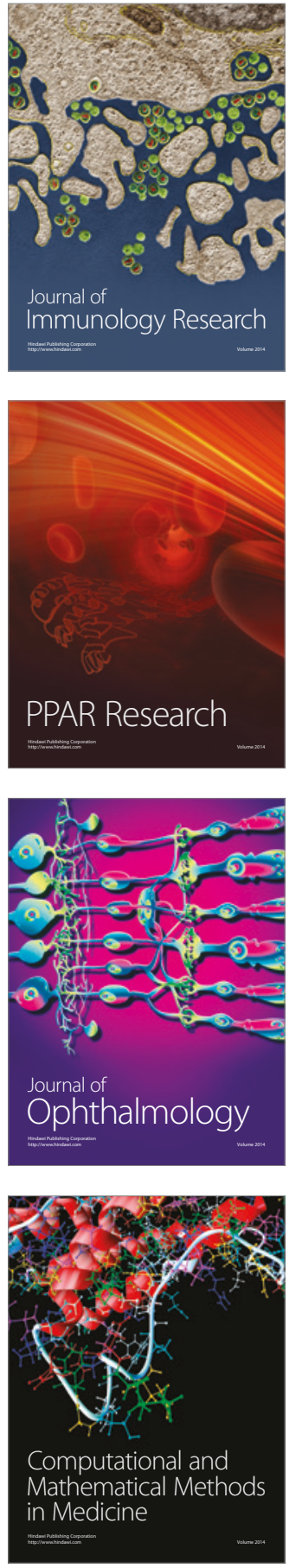

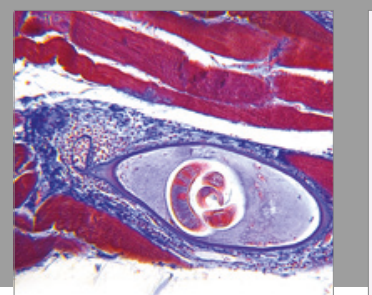

Gastroenterology Research and Practice
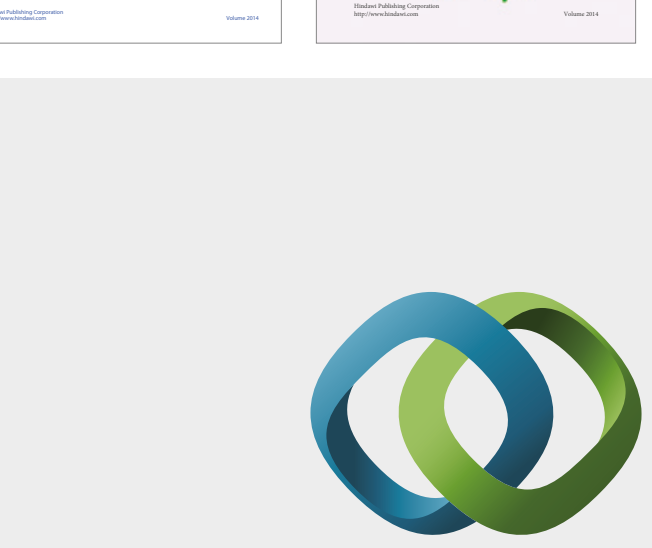

\section{Hindawi}

Submit your manuscripts at

https://www.hindawi.com
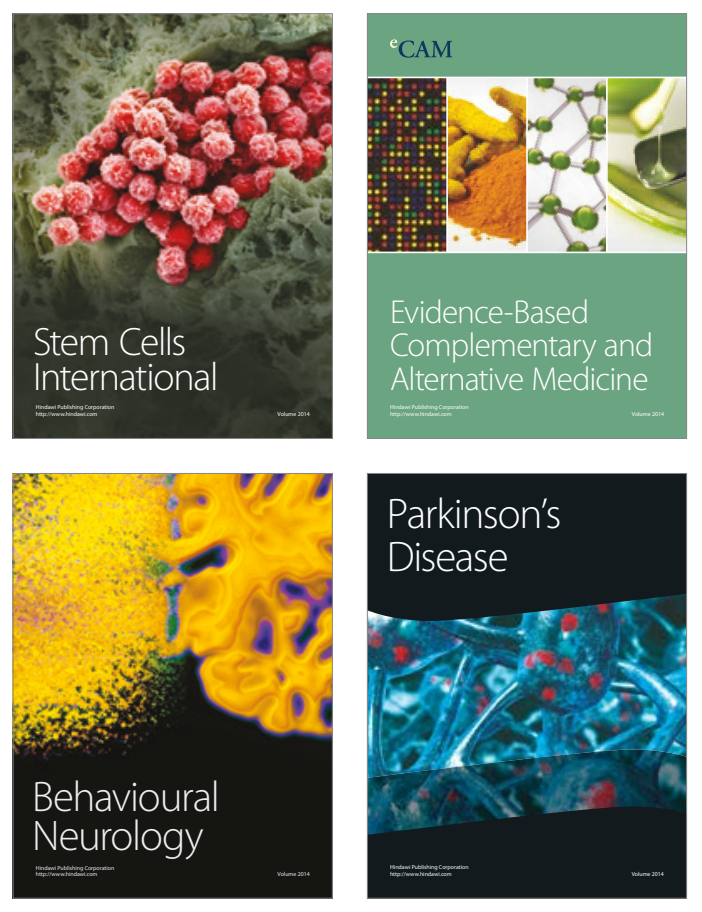
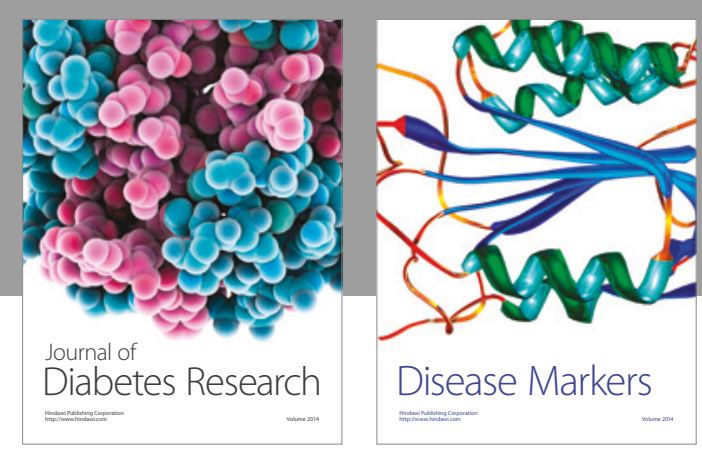

Disease Markers
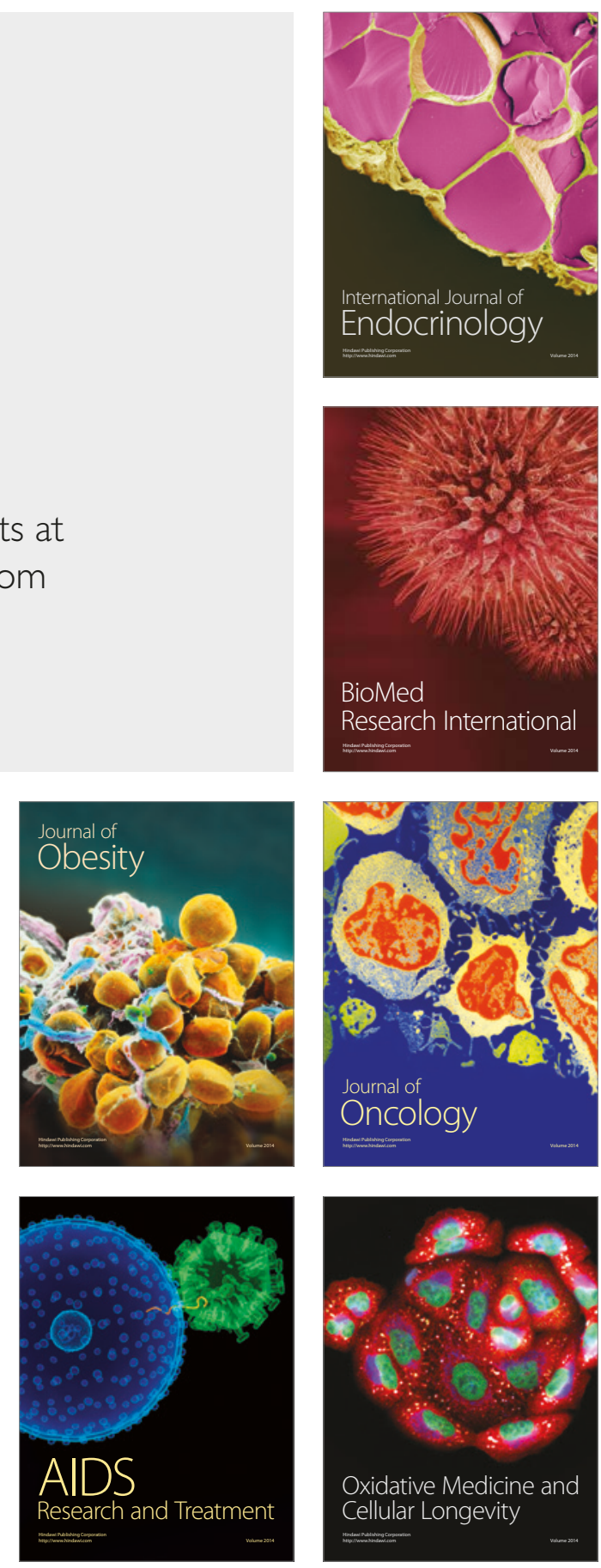